\title{
Case Report: Autoimmune Disease Triggered by Exposure to Hair Straightening Treatment Containing Formaldehyde
}

\author{
James Dahlgren $^{1}$, Rhett Roback ${ }^{1}$, Maria Dominguez ${ }^{1}$, Vera Byers ${ }^{2}$, David Silver ${ }^{3}$, Edward Faeder ${ }^{4}$ \\ ${ }^{1}$ James Dahlgren Medical, Santa Monica, USA; ${ }^{2}$ Immunology Inc., Incline Village, USA; ${ }^{3}$ UCLA David Geffen School of Medicine, \\ Los Angeles, USA; ${ }^{4}$ Srf Environmental \& Health Management Inc., Diamond Bar, USA. \\ Email: jamesgdahlgren@yahoo.com
}

Received November $2^{\text {nd }}, 2012$; revised December $5^{\text {th }}, 2012$; accepted December $17^{\text {th }}, 2012$

\begin{abstract}
Formaldehyde (FHO) is a multipurpose chemical that is an eye, nose, throat and skin irritant, sensitizer and allergen, as well as a class 1 human carcinogen. Brazilian hair treatments, containing high levels of FHO (up to 11\%), have become regularly used that have the potential to expose clients to toxic levels in excess of current regulatory standards. We report on a patient who underwent a single hair treatment and subsequently developed an autoimmune disease. We review the relevant literature on autoimmune disease and formaldehyde exposure. Our case adds to existing knowledge and suggests that physicians ask their patients about commercial products that contain formaldehyde when diagnosing autoimmune conditions.
\end{abstract}

Keywords: Formaldehyde; Autoimmune; Chemical Exposure; Brazilian Blowout; Hair Treatment

\section{Introduction}

Formaldehyde (FHO) is a colorless gas at room temperature with a pungent smell. Synonyms for FHO are numerous including, methanal, formalin, paraform, methylene glycol, methyl aldehyde, formol, formalin, formic aldehyde, paraform, formol, formalin (methanolfree), formalith, methylene oxide, tetraoxymethalene, oxomethane, morbicid acid and oxymethylene. The various names have the potential to confuse purchasers regarding FHO's presence in products. FHO in water is rapidly hydrated and in equilibrium with methylene glycol. The equilibrium favors methylene glycol. A thorough description of this process is offered in the doctoral thesis of Jozef Winkelman [1] and related publications arising from that work. Free FHO is released through heating the aqueous solution, and at sufficiently high temperature (e.g., above $\left.\approx 200^{\circ} \mathrm{C}\right)$ anhydrous $\mathrm{FHO}$ exists [2]. It is important to note that at room temperature $\left(25^{\circ} \mathrm{C}\right)$ relative humidity in the range of $50 \%$ contains enough water vapor (on the order of 10 grams per cubic meter) such that most of the FHO can rehydrate forming methylene glycol. This is especially true in the concentration range of greatest interest for FHO, less than 10 parts per million, which can be anticipated for extreme occupational exposures in a nonmanufacturing environment. Inhaled FHO will predominantly be in the form of me- thylene glycol, or will be converted shortly thereafter, in vivo, to that form because of the almost $100 \%$ relative humidity and liquid water present in living organisms. The rapid interconversion of FHO and methylene glycol, in vivo, has been postulated to be of primary concern related to the systemic toxicity and distribution to sites distal to the exposure route of entry into humans or animals exposed, primarily by inhalation [3]. Focus on products containing FHO by regulatory agencies has been on FHO and its chemical equivalents (e.g., methylene glycol), as these can cause frank toxicity and release FHO.

Individuals could be easily mislead and wrongly believe they have purchased an FHO-free product while still exposing themselves to FHO. It should be noted that formaldehyde does exist endogenously as a metabolic intermediate, but undergoes rapid metabolism by formaldehyde dehydrogenase to formate leading to little or no storage of free formaldehyde $[4,5]$. There is no evidence of toxicity from the low amounts of endogenous formaldehyde.

In 2011, the US Occupational Safety and Health Administration (OSHA), California Department of Public Health, Michigan OSHA, New York State Department of Health, and Health Canada produced warnings to consumers about the potential dangers of formaldehyde (FHO) exposure from popular hair-straightening products, 
including products that reportedly were FHO free [6-10]. Small quantities of FHO are commonly used in cosmetics. The European Union allows up to $0.2 \%$ free FHO in cosmetics and requires warning labels if a product contains more than $0.05 \%$ FHO [11]. In contrast, the United States Food and Drug Administration (FDA) permits companies to use FHO without specific limits. Recently, hair-straightening products from Brazil, containing up to $11.8 \%$ formaldehyde, have become popular. The FHO at these higher levels effectively straightens hair and allows the treatment to last longer [8].

FHO and its chemical equivalents present in hair straightening products undergo dramatic heating steps. The heating increases the peak FHO release into the breathing zone of the salon personnel and their customers. A simulated study of FHO levels during treatment with a hair-straightening product with $11.5 \%$ (by weight) formaldehyde on a mannequin revealed a 15 -minute air concentration of 3.75 parts-per-million (ppm) for the surrogate customer and $2.41 \mathrm{ppm}$ for the stylist. These levels are above the Short Term Exposure Level (STEL) of 2 ppm set by the US Occupational Safety and Health Administration (OSHA). The STEL recommended by the US National Institute of Occupational Safety and Health (NIOSH) is $0.1 \mathrm{ppm}$ and by the American Conference of Governmental Hygienists (ACGIH) is $0.3 \mathrm{ppm}$. The eight hour time weighted average for FHO in the salon also exceeded recommended levels [12]. NIOSH studied hair salon FHO air levels during use of the hair-straightening product with $11 \%$ formaldehyde and found a short-term peak of $1.3 \mathrm{ppm}$ [13]. Oregon OSHA found similar peak values of FHO in the stylist breathing zone [14].

The recognized irritant effects of exposure to FHO include 1) eye, nose and throat irritation, 2) loss of sense of smell, 3) increased upper respiratory disease, 4) dry and sore throats, 5) respiratory tract irritation, 5) cough, 6) chest pain, 7) dyspnea and 8) wheezing. NIOSH and others reported primary skin irritation and allergic dermatitis from contact with water solutions of FHO [5,14,15], as well as genotoxicity and human carcinogenicity $[3,4]$. FHO has also been shown to be mutagenic. A study of Brazilian hairdressers who had been exposed to FHO as well as other chemicals showed significant DNA damage [16]. Mutagenicity testing revealed positive results from exposure to hair straightening creams containing FHO [17]. Formaldehyde has also been reported to cause or aggravate asthma in exposed workers [18-21].

The presented case report is unique because of the exposure route and the subsequent development of an autoimmune disease. Autoimmune diseases are a grouping of complex disorders characterized by the breakdown of immunologic self-recognition and the subsequent immune system attack on otherwise healthy tissue. Autoimmune diseases include Grave's disease, Hashimoto's thyroiditis, multiple sclerosis and rheumatoid arthritis.
An estimated 1.2 million cases of autoimmune diseases are diagnosed every five years in the United States [22] with prevalence estimates of $7.6 \%-9.4 \%$ [23]. Many factors have been implicated in autoimmune disease causation including chemicals, infectious agents, food constituents and radiation $[24,25]$.

We report a case of an autoimmune disease triggered by exposure to formaldehyde contained in a hair-straightening product. We review the literature on the relationship of formaldehyde exposure and immune system dysfunction.

\section{Case Presentation}

In September 2010, a 47-year-old female underwent a "Brazilian Blowout" treatment to straighten her hair. This procedure used a solution applied directly to hair and was followed by blow drying, and then heating the hair with a 450-degree flat iron. The patient was told that the solution contained no formaldehyde or harsh chemicals. The product's label indicated that it was "Formaldehyde-Free". This patient had a history of an adverse reaction, consisting of skin redness and swelling, from sutures containing formaldehyde. The hair treatment lasted approximately three hours. She experienced a strong odor followed by a burning sensation in her eyes, nose and throat for a short time when the heated iron was applied. The usual procedure was to wash the chemical out of the hair prior to departure; however, the treatment lasted until closing time so she was told to leave the solution on her hair until her next scheduled appointment. Over the next few days, she developed diarrhea, vomiting, total body flushing and low-grade fever. On day eight post-exposure, she felt a burning sensation on her scalp, and subsequently washed her hair that day. While in the shower, at a water temperature of approximately $40^{\circ} \mathrm{C}$, she developed difficulty breathing and felt, "fumes coming off me like someone was using lots of spray bottles." Shortly thereafter, she experienced the onset of recurrent epistaxis, which continued for months. At that point, she sought medical assistance. The emergency room physician told her that she had sores and bald spots consistent with chemical burns on her scalp and lesions in her mouth.

Over the next three months she lost 25 pounds due to gastrointestinal symptoms. She was unable to eat, did not have bowel movements for 2 to 3 weeks at a time, and had intermittent bloating and abdominal pain, which required hospitalization. She was diagnosed with pancreatitis, but the etiology was not determined. Her skin turned bright red all over her body when she took a shower. She developed tachycardia and total body tingling that would come on 10 to 15 times a day, frequently lasting from 10 to 15 minutes and sometimes up to 60 minutes. Her 
menses stopped one-month post-exposure. Formaldehyde air measurements near the patient's hair were performed 76 days post-exposure by a Certified Industrial Hygienist (CIH). The formaldehyde air concentration near her head was $150 \mathrm{ppb}$ when the hygienist applied the hot iron to her hair. For comparison, this is above California's allowable formaldehyde level from off-gassing of wood products [26]. This level is also above California's acute reference exposure level for FHO of 44 parts per billion (ppb), for a period of one hour [27]. The patient had all of her hair removed following the exposure test results. The bottle of hair solution used on the patient was tested and found to have $8.6 \% \mathrm{FHO}$ equivalents by weight, in direct opposition to the label, which stated "Formaldehyde-Free." This is equivalent to almost $13.8 \%$ methylene glycol, greatly exceeding the $<5 \%$ methylene glycol level stated on the material safety data sheet produced by the manufacturer [28].

Her health continued to deteriorate. A series of doctors evaluated and treated her over the subsequent months. A diagnosis of an autoimmune disease, not otherwise classified, was made based on multiple organ impairment including peripheral neuropathy, anemia, joint and muscle pain, fever, flushing, weakness, amenorrhea, fatigue and weakness. Several physicians observed Raynaud's phenomenon with minimal cold exposure lasting only a few seconds. A positive Anti-Nuclear Antibodies (ANA) of 1:160 (centromere pattern), positive anti-neuronal antibodies, reduced complement C3-37 mg/dl (normal 79 - 152) and reduced complement C4 10 mg/dl (normal 16 - 47) confirmed the presence of an autoimmune disease. A negative ANA had been performed in 2007. Treatment with plasmaphoresis began in 2011, which improved her symptoms and she continues to receive this therapy three times per week. She has been unable to tolerate other immune suppressant therapy.

Prior to the exposure to the Brazilian Blowout treatment, the patient had a thorough medical evaluation to evaluate her health and suitability for in vitro fertilization. She was found to be healthy and able to tolerate pregnancy. Her only medical problems were musculoskeletal and neurological residuals from an injury sustained in 2003.

As a result of her serious health problems, the patient initiated a lawsuit against the manufacturer of her hair treatment compound.

\section{Discussion}

There are numerous studies associating formaldehyde exposure with negative health effects. Table 1 lists human studies of formaldehyde-induced immune effects. Galiotte et al. studied the genotoxic risk of Brazilian hairdressers and found a higher frequency of DNA damage $(159.8+\backslash-71)$ when compared to the control group $(125.4+\backslash-64.1)$ as assessed by Comet assay scores $(\mathrm{P}=$ $0.005)$ [16]. Although indoor air in a beauty salon environment contains many chemicals other than formaldehyde $[29,30]$, it is reasonable to assume that formaldehyde played a significant role in the measured DNA damage. Mazzei et al. reported significant $(\mathrm{P}<0.05)$ positive mutagenicity induction in a Salmonella/microsome assay and $\beta$-galactosidase induction in the SOS chromotest in Escherichia coli PQ37 and OG100 strains in homemade hair-straightening creams with high formaldehyde content [17].

Pierce et al. conducted an exposure study using four different straightening compounds (Coppola, Brazilian Blowout, Global Keratin, La Brasiliana) applied to a mannequin by a professional hair stylist and heated by flat-iron and blow dryer [12]. Measurements showed that airborne formaldehyde levels could exceed occupational exposure limits, especially while using the Brazilian Blowout compound. Peak exposure of 3.47 ppm (range 3.36 3.59) was found during blow drying, which exceeds OSHA STEL (15 minute, 2 ppm) and ACGIH TLV-C (ceiling, $0.3 \mathrm{ppm}$ ) limits. When four treatments were performed, the NIOSH and ACGIH eight hour time weighted average was exceeded.

NIOSH measured airborne formaldehyde in an Ohio salon during a single Brazilian Blowout treatment and found levels of $1.3 \mathrm{ppm}$ during application, and $0.9 \mathrm{ppm}$ during blow drying [13]. These levels exceed the NIOSH ceiling limit ( $0.1 \mathrm{ppm})$ and the ACGIH limit of $0.3 \mathrm{ppm}$. NIOSH also measured $11 \%$ formaldehyde in the Brazilian Blowout product, and concluded that, "The hair salon [should] discontinue the use of the Brazilian Blowout Acai Professional Smoothing Solution-Formaldehyde Free Formula product" [13]. Although the manufacturers of certain products claim their products are formaldehyde-free, Oregon OSHA, federal OSHA and the American Chemistry Council consider formaldehyde-in-water (formalin) to be equivalent to formaldehyde with respect to exposure monitoring [14,31] and therefore, products containing formalin should not be marked "formaldehyde free".

In response to health concerns from a local hair stylist, the Center for Research in Occupational and Environmental Toxicology (CROET) at the Oregon Health Sciences University (OHSU) and Oregon OSHA conducted exposure assessments for 54 hair salons [14]. They found 8-hour average exposures ranging from 0.006 to 0.33 ppm for individual treatments of Brazilian Blowout, which exceeds ACGIH and NIOSH recommendations and is nearly $50 \%$ of the recommended OSHA 8-hour limit. Formaldehyde was found in concentrations of $6.8 \%-11.8 \%$ (mean 8.8\%) for samples of "Brazilian Blowout Acai Professional Smoothing Solution", labeled "formaldehyde 
Table 1. Human studies of formaldehyde-related immune effects.

\begin{tabular}{|c|c|c|c|}
\hline Study & Subjects & Exposure & Findings \\
\hline Breysse et al. [33] & $\begin{array}{l}4 \text { patients with membranous } \\
\text { nephropathy }\end{array}$ & $0.1-0.49$ ppm FHO & $\begin{array}{l}\text { Autoimmune glomerulitis, mild eosinophoilia, low-positive } \\
\text { ANA, borderline-low } \mathrm{C} 4 / \mathrm{CH} 50\end{array}$ \\
\hline Thrasher et al. [35] & $\begin{array}{l}\text { Controls (28), individuals living in } \\
\text { mobile homes (19), office workers } \\
\text { (21), previously exposed } \\
\text { individuals (21) }\end{array}$ & $\sim 0.01 \mathrm{ppm}-1 \mathrm{ppm}$ FHO & $\begin{array}{l}\text { Increased antibodies to FHO serum albumin, } \\
\text { anti-myelin auto-antibodies. Significant increases in Ta1+, } \\
\text { IL } 2+\text {, and B cells }\end{array}$ \\
\hline Hosgood et al. [41] & $\begin{array}{l}43 \text { formaldehyde-exposed workers } \\
\text { and } 51 \text { unexposed age and } \\
\text { sex-matched controls }\end{array}$ & $\begin{array}{l}\text { Mean } 1.28 \mathrm{ppm} \\
(\sim 0.63-2.51 \mathrm{ppm}) \mathrm{FHO} \\
>3 \text { month duration }\end{array}$ & $\begin{array}{c}\text { Decreased NK cell, CD8+ T, CD8+ effector memory T, } \\
\text { regulatory T cell counts }\end{array}$ \\
\hline Patterson et al. [36] & $\begin{array}{l}18 \text { patients undergoing dialysis } \\
\text { using FHO-sterilization, } 9 \\
\text { FHO-exposed healthcare workers }\end{array}$ & $\begin{array}{l}\text { Variable with known } \\
\text { symptoms and no known } \\
\text { symptoms subjects }\end{array}$ & $\begin{array}{l}\text { Positive measurement of anti FHO-HAS antibodies in } \\
\text { patients }\end{array}$ \\
\hline Fassbinder et al. [34] & 270 dialysis patients & $\begin{array}{l}\text { FHO exposure via sterilization of } \\
\text { dialyzer. }\end{array}$ & $\begin{array}{l}\text { Anti-N-like antibody in 60/270. Positive trend with FHO } \\
\text { sterilization (versus no FHO use) and antibody occurrence }\end{array}$ \\
\hline
\end{tabular}

free" and 6.4\% - 10.8\% (mean 8\%) for Brazilian Blowout without "formaldehyde-free" labeling. A limited number of other solution samples were taken and showed formaldehyde concentrations substantially lower than Brazilian Blowout.

According to the US Food and Drug Administration (FDA) records, obtained by the Environmental Working Group through a Freedom of Information Act request, the FDA has received 47 complaints (time period ending January 2011) from users and stylists of hair straightening products [32].

Given the substantial amount of evidence indicating airborne formaldehyde exposure potential from individual treatments, it is plausible and likely that real-world exposures would be significantly higher if multiple treatments are performed in close proximity and within similar time-periods. This would correlate to greater potential for negative health outcomes for both customers and stylists, assuming proper exposure control protocols are not used.

Breysse et al. reported four patients with formaldehyde exposure from $0.1-0.49$ ppm who developed autoimmune glomerulitis [33] and had atypical features including mild eosinophilia (two patients), low-positive antinuclear antibody levels with a negative anti-doublestranded DNA antibody test result (two patients), and borderline-low $\mathrm{C} 4$ (one patient) or $\mathrm{CH} 50$ (one patient) [33]. Autoimmune hemolytic anemia has been reported in dialysis patients after FHO sterilization of dialyzers [34].

Formaldehyde exposure in three groups with FHO exposure was studied for autoimmune disease markers. These groups were A. mobile homes, B. office workers (FHO exposed from new paint) and C. high FHO exposure from occupations including mortuaries and laboratories. These groups had significantly increased autoantibodies to formaldehyde serum albumin (FHO-HSA) compared to the controls. The FHO exposed groups also had significantly increased occurrence of ANA as well as several other autoantibodies. Antimyelin auto-antibodies were present in subjects with nervous system symptoms. The study was unable to determine if any of the subjects had been diagnosed with an autoimmune disease. Thrasher et al. also found significant increases in Ta1+, IL2+, and $\mathrm{B}$ cells in the subjects when comparing individuals exposure to the controls [35].

Studies of kidney dialysis patients exposed to formaldehyde revealed positive $\mathrm{IgG}$ antibodies to formaldehyde-albumin (F-HSA) adducts. The authors also studied two nurses who had positive antibody titers to the adducts and formaldehyde induced asthma. The dialysis patients did not exhibit any relationship between the antibodies and clinical abnormalities [36].

Links between formaldehyde and adverse effects on the immune system are well documented. Arts and colleagues applied formaldehyde to the skin of rats and found significant dose-dependant increases in lymph node weight and proliferative activity [37]. These authors concluded that FHO causes an immune response but it is not mediated by IgE. Fujimaki et al. evaluated the immunogenic effects of inhaled formaldehyde on female $\mathrm{C} 3 \mathrm{H} / \mathrm{He}$ mice to $0,0.080,0.400$, or $2.000 \mathrm{ppm}$ formaldehyde for 12 weeks [38]. Mice immunized with ovalbumin and then exposed to $2000 \mathrm{ppb}$ formaldehyde had increased numbers of total bronchoalveolar lavage cells, macrophages, and eosinophils compared with controls, although the production of interleukin- $1 \beta$ from broncho-alveolar lavage fluid of these mice decreased significantly. These results provided the first experimental evidence that low levels of formaldehyde inhalation can induce differential immunogenic and neurogenic responses in allergic mice. Riedel et al. found that short-term exposure to low concentrations of formaldehyde (250 ppb) was sufficient to significantly enhance sensitization 
to inhaled allergens in guinea pigs [39]. Similarly, Swiecichowski et al. found that formaldehyde exposure caused broncho-constriction and increased sensitivity to acetylcholine at either $>0.3 \mathrm{ppm}$ for an eight hour exposure or similar effects at $>9 \mathrm{ppm}$ for two hour exposures in guinea pigs [40]. Formaldehyde exposure was also found to heighten airway smooth muscle responsiveness to acetylcholine (or carbachol) ex vivo. Workers exposed to FHO at $1.28 \mathrm{ppm}$ time weighted over eight hours experienced decreased counts of NK cells, regulatory $\mathrm{T}$ cells, and CD8+ effector memory T cells [41].

\section{Conclusion}

The sequence of events in this case is best explained by a sub-acute exposure to FHO inducing an exaggerated immune response. This abnormal immune response altered the body's ability to distinguish self antigens leading to this life-threatening autoimmune disease. Physicians should seek information on $\mathrm{FHO}$ exposure in patients presenting with autoimmune disease. It must be remembered that FHO often is not stated on product labels and sometimes a label misleads the user by failing to list the multiple other terms used for chemicals that release FHO in the normal course of use for the product.

\section{Disclosure Statement}

Dr. Dahlgren, Dr. Byers and Dr. Silver serve as expert witness/consultants in civil cases. All acted as experts for the reported case. Original funding for the assessment of the patient was provided by law firms representing her in a civil lawsuit. The writing of the manuscript was entirely funded by the corresponding author. The law firms were not involved at all in the writing of the report, and it was not written for the purposes of litigation.

\section{REFERENCES}

[1] J. Winkelman "Absorption of Formaldehyde in Water," University of Groningen, Groningen, 2003.

[2] N. Matubayasi, S. Morooka, M. Nakahara and H. Takahashi, "Chemical Equilibrium of Formaldehyde and Methanediol in Hot Water: Free-Energy Analysis of the Solvent Effect," Journal of Molecular Liquids, Vol. 134, No. 1-3, 2007, pp. 58-63. doi:10.1016/j.molliq.2006.12.002

[3] National Toxicology Program, "Report on Carcinogens," 12th Edition, US Department of Health and Human Services PHS, Research Triangle Park, 2011.

[4] International Agency for Research on Cancer, "Formaldehyde, 2-Butoxyethanol and 1-tert-Butoxypropan-2-ol," IARC Monographs, Vol. 88, 2006, pp. 1-436.

[5] Agency for Toxic Substances and Disease Registry, "Toxicological Profile for Formaldehyde," US Department of Health and Human Services PHS, Atlanta, 1999.

[6] Michigan Occupational Safety and Health Administration,
"Hair Straightening Products and Formaldehyde (Fact Sheet \#022)," Division GISH, Lansing, Michigan, 2011.

[7] Health Canada, "Several Professional Hair Smoothing Solutions Contain Excess Levels of Formaldehyde," 2011.

[8] California Department of Public Health, "Q\&A: Brazilian Blowout \& Other Hair Smoothing Salon Treatments," Branch CSCPOH, Sacramento, 2011.

[9] New York State Department of Health, "Consumer Health Alert: Hair Straightening Products and Formaldehyde," Health CfE, Troy, 2011.

[10] Occupational Safety and Health Administration, "Hair Smoothing Products That Could Release Formaldehyde," Labor UDo, 2011.

[11] European Union, "Eighth Commission Directive of 26 March 1986 adapting to technical progress Annexes II, IV and VI to Council Directive 76/768/EEC on the Approximation of the Laws of the Member States Relating to Cosmetic Products," Official Journal of the European Communities, Vol. 15, 1986, p. 0150.

[12] J. S. Pierce, A. Abelmann, L. J. Spicer, R. E. Adams, M. E. Glynn, K. Neier, et al., "Characterization of Formaldehyde Exposure Resulting from the Use of Four Professional Hair Straightening Products," Journal of Occupational and Environmental Hygiene, Vol. 8, No. 11, 2011, pp. 686-699. doi:10.1080/15459624.2011.626259

[13] National Institute of Occupational Safety and Health, "Formaldehyde Exposures during Brazilian Blowout Hair Smoothing Treatment at a Hair Salon-Ohio," Control CfD, Cincinnati, 2011.

[14] K. M. D. McCarthy, D. Montgomery, P. Munsell, M. Schuster and M. Wood, "Keratin-Based Hair Smoothing Products and the Presence of Formaldehyde," Oregon OSHA COHSU, Portland, 2010.

[15] P. A. Breysse, "The Immediate and Long-Term Effects of Formaldehyde," Comments on Toxicology, Vol. 3, No. 2, 1988, pp. 135-153.

[16] M. P. Galiotte, P. Kohler, G. Mussi and G. J. Gatta, “Assessment of Occupational Genotoxic Risk among Brazilian Hairdressers," The Annals of Occupational Hygiene, Vol. 52, No. 7, 2008, pp. 645-651.

doi:10.1093/annhyg/men037

[17] J. L. Mazzei, E. V. Figueiredo, L. J. da Veiga, C. A. Aiub, P. I. Guimaraes and I. Felzenszwalb, "Mutagenic Risks Induced by Homemade Hair Straightening Creams with High Formaldehyde Content," Journal of Applied Toxicology: JAT, Vol. 30, No. 1, 2010, pp. 8-14. doi:10.1002/jat.1464

[18] P. S. Burge, M. G. Harries, W. K. Lam, I. M. O’Brien and P. A. Patchett, "Occupational Asthma Due to Formaldehyde," Thorax, Vol. 40, No. 4, 1985, pp. 255-260. doi:10.1136/thx.40.4.255

[19] D. J. Hendrick and D. J. Lane, "Formalin Asthma in Hospital Staff," British Medical Journal, Vol. 1, No. 5958, 1975, pp. 607-608. doi:10.1136/bmj.1.5958.607

[20] C. W. Kim, J. S. Song, Y. S. Ahn, S. H. Park, J. W. Park, J. H. Noh, et al., "Occupational Asthma Due to Formaldehyde," Yonsei Medical Journal, Vol. 42, 2001, pp. 440445 . 
[21] H. Nordman, H. Keskinen and M. Tuppurainen, "Formaldehyde Asthma-Rare or Overlooked?" The Journal of Allergy and Clinical Immunology, Vol. 75, No. , 1985, pp. 91-99. doi:10.1016/0091-6749(85)90018-1

[22] D. L. Jacobson, S. J. Gange, N. R. Rose and N. M. Graham, "Epidemiology and Estimated Population Burden of Selected Autoimmune Diseases in the United States," Clinical Immunology and Immunopathology, Vol. 84, No. 3, 1997, pp. 223-243. doi:10.1006/clin.1997.4412

[23] G. S. Cooper, M. L. Bynum and E. C. Somers, "Recent Insights in the Epidemiology of Autoimmune Diseases: Improved Prevalence Estimates and Understanding of Clustering of Diseases," Journal of Autoimmunity, Vol. 33, No. 3-4, 2009, pp. 197-207. doi:10.1016/j.jaut.2009.09.008

[24] M. E. B. N. Kammuller and W. Seinen, "Autoimmunity and Toxicology Immune Disregulation Induced by Drugs and Chemicals," Elsevier, Amsterdam, 1989.

[25] E. V. Hess, "Environmental Chemicals and Autoimmune Disease: Cause and Effect," Toxicology, Vol. 181-182, 2002, pp. 65-70. doi:10.1016/S0300-483X(02)00256-1

[26] California Air Resources Board, "Airborne Toxic Control Measure to Reduce Formaldehyde Emissions from Composite Wood Products," Agency CEP, Sacramento, 2008.

[27] California Office of Environmental Health Hazard Assessment, "All OEHHA Acute, 8-Hour and Chronic Reference Exposure Levels (chRELs) as on February 2012," Agency CEP, Sacramento, 2012.

[28] Brazilian Blowout, "Brazilian Blowout Professional Smoothing Solution," MSDS Revision 1.4, Tujunga Ave, North Hollywood, 2010.

[29] A. Tsigonia, A. Lagoudi, S. Chandrinou, A. Linos, N. Evlogias and E. C. Alexopoulos, "Indoor Air in Beauty Salons and Occupational Health Exposure of Cosmetologists to Chemical Substances," International Journal of Environmental Research and Public Health, Vol. 7, No. 1, 2010, pp. 314-324. doi:10.3390/ijerph7010314

[30] E. Ronda, B. E. Hollund and B. E. Moen, "Airborne Exposure to Chemical Substances in Hairdresser Salons," Environmental Monitoring and Assessment, Vol. 153, No. 1-4, 2009, pp. 83-93. doi:10.1007/s10661-008-0338-y

[31] B. Goodman, "Position Statement of the American Chemistry Council's Formaldehyde Panel on the Formaldehyde Content of Certain Hair-Care Products," Council AC, Washington, 2010.

[32] Environmental Working Group, "Adverse Reactions and
Injuries," Flat-Out Risky, Washington, 2011.

[33] P. Breysse, W. G. Couser, C. E. Alpers, K. Nelson, L. Gaur and R. J. Johnson, "Membranous Nephropathy and Formaldehyde Exposure," Annals of Internal Medicine, Vol. 120, No. 120, 1994, pp. 396-397.

[34] W. Fassbinder and K. M. Koch, "A Specific Immunohaemolytic Anaemia Induced by Formaldehyde Sterilisation of Dialysers," Contributions to Nephrology, Vol. 36, 1983, pp. 51-67.

[35] J. D. Thrasher, A. Broughton and R. Madison, "Immune Activation and Autoantibodies in Humans with LongTerm Inhalation Exposure to Formaldehyde," Archives of Environmental Health, Vol. 45, No. 4, 1990, pp. 217-223. doi:10.1080/00039896.1990.9940805

[36] R. Patterson, V. Pateras, L. C. Grammer and K. E. Harris, "Human Antibodies against Formaldehyde-Human Serum Albumin Conjugates or Human Serum Albumin in Individuals Exposed to Formaldehyde," International Archives of Allergy and Applied Immunology, Vol. 79, No. 1, 1986, pp. 53-59. doi:10.1159/000233942

[37] J. H. E. Arts, S. C. M. Dröge, S. Spanhaak, N. Bloksma, A. Penninks and C. F. Kuper, "Local Lymph Node Activation and IgE Responses in Brown Norway and Wistar Rats after Dermal Application of Sensitizing and NonSensitizing Chemicals," Toxicology, Vol. 117, No. 2-3, 1997, pp. 229-237. doi:10.1016/S0300-483X(96)03576-7

[38] H. Fujimaki, Y. Kurokawa, N. Kunugita, M. Kikuchi, F. Sato and K. Arashidani, "Differential Immunogenic and Neurogenic Inflammatory Responses in an Allergic Mouse Model Exposed to Low Levels of Formaldehyde," Toxicology, Vol. 197, No. 1, 2004, pp. 1-13. doi:10.1016/j.tox.2003.11.015

[39] F. Riedel, E. Hasenauer, P. J. Barth, A. Koziorowski and C. H. L. Rieger, "Formaldehyde Exposure Enhances Inhalative Allergic Sensitization in the Guinea Pig," Allergy, Vol. 51, No. 2, 1996, pp. 94-99.

[40] A. L. Swiecichowski, K. J. Long, M. L. Miller and G. D. Leikauf, "Formaldehyde-Induced Airway Hyperreactivity in Vivo and ex Vivo in Guinea Pigs," Environmental Research, Vol. 61, No. 2, 1993, pp. 185-199. doi:10.1006/enrs.1993.1063

[41] H. D. Hosgood, L. Zhang, X. Tang, R. Vermeulen, Z. Hao, M. Shen, et al., "Occupational Exposure to Formaldehyde and Alterations in Lymphocyte Subsets," American Journal of Industrial Medicine, Vol. 56, No. 2, 2013, pp. 252-257. 